\title{
Clinical Profile and Prognosis of Patients with Right Ventricular Dilated Cardiomyopathy: Results of a Prospective Study
}

\author{
Ya.R. Akhmatov ${ }^{1 *}$; T.A. Abdullayev ${ }^{1}, \mathrm{PhD}, \mathrm{ScD}$; B.U. Mardanov ${ }^{2}$. \\ ${ }^{1}$ The Republican Specialized Center of Cardiology, Tashkent, Uzbekistan \\ ${ }^{2}$ National Research Centre for Preventive Medicine, Moscow, Russia
}

\begin{abstract}
The aim of our study was to investigate the clinical prevalence of dilated cardiomyopathy (DCM) with predominantly failure of the right-side heart (right ventricular DCM, RV-DCM), and features of the clinical course and prognosis of the disease compared to DCM with biventricular heart failure (BV-HF).

The study design suggests a prospective observation of 300 patients with idiopathic DCM between 2000 and 2012. Herewith, we followed the criteria of the WHO/ISFC task force (1995) on the definition and classification of cardiomyopathies. All patients underwent a comprehensive examination. Two groups were formed for further comparative analysis. Group 1 included 22 patients (mean age $42.9 \pm 14.3$ years, male/female 5/17) with RV-DCM. Group 2 included 38 patients (mean age $43.6 \pm 13.8$, male/female 29/9) with DCM and BV-HF. The groups were matched for age, NYHA class II-III, and disease duration. According to our aim, we studied 5-year survival prognosis and analyzed the incidence and causes of deaths, as well as the occurrence of nonfatal complications of the disease. Medical therapy for DCM patients was performed according to the CHF therapy guidelines (ACC/ AHA 2001, 2005).The results of our investigations during many years of research have shown that the clinical incidence of RV-DCM was 7.3\% among all forms of DCM. The study of life prognosis in patients with 2 forms of DCM showed that 5-year mortality of patients was about 50\%. Fatal pulmonary embolism was a leading cause (50\%) in RV-DCM patients. (Int J Biomed. 2015;5(4):207-213.)
\end{abstract}

Keywords: right ventricular dilated cardiomyopathy, biventricular heart failure, prognosis; pulmonary embolism.

\section{Abbreviations}

RV-DCM, right ventricular dilated cardiomyopathy; CHF, chronic heart failure; BV-HF, biventricular heart failure; LVM, left ventricular mass; LVEDD, LV end-diastolic dimension; LVESD, LV end-systolic dimension; LVEDV, LV end-diastolic volume; LVESV, LV end-systolic volume; LVSV, LV stroke volume; LVFS, LV fractional shortening; LA left atrium; RA, right atrium; IVST, interventricular septal thickness; LVPWT, LV posterior wall thickness; EF, ejection fraction; ARVD, arrhythmogenic RV dysplasia; AF, atrial fibrillation; PEmb, pulmonary embolism; PE, peak early filling velocity; PA, peak atrial filling velocity; LBBB, left bundle branch block; RBBB, right bundle branch block.

\section{Introduction}

The idiopathic nature of right ventricle failure was first described by A. Bahler in 1976 [1]. Describing two cases of RV dilatation and paradoxical movement of the interventricular septum in the absence of any disease or heart disease, the authors suggested that there are certain initial symptoms of

*Corresponding author: Yashin R. Akhmatov. The Republican Specialized Center of Cardiology, Tashkent, Uzbekistan. E-mail: dr.yashin@mail.ru cardiomyopathy. Afterwards, the report of WHO/ISFC task force defined cardiomyopathies as diseases of the myocardium associated with cardiac dysfunction and classified the forms of diseases, including DCM with its varieties [2]. The international recommendations to date have provided clear criteria for the diagnosis of alcoholic, peripartum cardiomyopathy and family forms of cardiomyopathy [35]. There are a lot of controversial issues related to both the diagnosis and treatment of DCM with predominantly failure of the right ventricle (not to be confused with ARVD). Isolated idiopathic RV-DCM is an equally rare condition like the 
familial RV-DCM. Besides the few reports which had been mentioned casually, there are only a few documented cases in the literature. [6-9].The severity of the problem is heightened by a significant limitation of publications related to the clinical course and prognosis precisely of RV-DCM.

Based on the above, the aim of our study was to investigate the clinical prevalence of DCM with predominantly failure of the right-side heart (RV-DCM), and features of the clinical course and prognosis of the disease compared to DCM with BV-HF.

\section{Materials and Methods}

The study design suggests a prospective observation of 300 patients with idiopathic DCM between 2000 and 2012 in the Department of Heart Failure and Noncoronary Myocardial Pathology at RSCC. Herewith, we followed the criteria of the WHO/ISFC Task Force (1995) on the Definationa and Classification of Cardiomyopathies [2]. RVDCM was diagnosed according to the above criteria and the additional exclusion of other conditions characterized by dilatation and right-sided heart failure (primarily ARVD, idiopathic and secondary pulmonary hypertension), as well as clinical, electrocardiographic, and echocardiographic features that were systematized later and proposed as criteria for diagnosis [3]. In addition, to assess the clinical status, the patients underwent 6-minute walk test (6MWT), a standard electrocardiogram («Cardio Lab», Ukraine), transthoracal echocardiography (Siemens Sonoline Verso Pro) at rest by common methods to determine the volumetric and linear heart parameters with calculation of LV myocardial contractility by Teicholz method. We used R. Levine's, T. Gibson's at al. formula: $\quad$ RVEF $\%=($ RVEDV-RVESV $) /$ RWEDV $) \cdot 100 \%$ for the calculation of RVEF $[10,11]$. Biochemical and immune enzyme analyses were also carried out.

In the course of examination of patients, two groups were formed for further comparative analysis. Group 1 included 22 patients (mean age $42.9 \pm 14.3$ years, male/female 5/17) with RV-DCM. Group 2 included 38 patients (mean age 43.6 \pm 13.8 , male/female 29/9) with DCM and BV-HF. The groups were matched for age, NYHA class II-III, and disease duration. According to our aim, we studied 5-year survival prognosis and analyzed the incidence and causes of deaths, as well as the occurrence of nonfatal complications of the disease.

Medical therapy for DCM patients was performed according to the ACC/AHA 2001, 2005 Guidelines.

Statistical analysis was performed using using the statistical software "Biostatics" (v.4.03"). Baseline characteristics were summarized as frequencies and percentages for categorical variables and as mean \pm SEM for continuous variables. Student's unpaired and paired t-tests were used to compare two groups for data with normal distribution. Group comparisons with respect to categorical variables are performed using chi-square tests or, alternatively, Yates' $\chi 2$ when expected cell counts were less than 5 . A probability value of $P<0.05$ was considered statistically significant.

The study was conducted in accordance with ethical principles of the Declaration of Helsinki and approved by the Republican Specialized Center of Cardiology Ethics Committee. Written informed consent was obtained from each patient.

\section{Results}

During the study period, we had the opportunity to assess the clinical and hemodynamic parameters of the patients; readmissions frequency and outcomes were recorded, including an active remote observation. The initial patients' characteristics - clinical and functional, anamnestic, gender and hemodynamic - are shown in Table 1. The vast majority of our patients (77\%) identified with RV-DCM were female, while almost all epidemiological studies suggest that DCM as a whole is more common in men. The patients' mean age (more than 40 years), as well as the age when the disease manifested, was comparable in both groups.

Table 1.

The initial patients' characteristics

\begin{tabular}{|l|c|c|c|}
\hline \multicolumn{1}{|c|}{ Variable } & $\begin{array}{c}\text { Group 1 } \\
(\mathrm{n}=22)\end{array}$ & $\begin{array}{c}\text { Group 2 } \\
(\mathrm{n}=38)\end{array}$ & $P$ \\
\hline Average age, years & $42.9 \pm 14.3$ & $43.6 \pm 13.8$ & $N S$ \\
\hline Male/female & $6 / 16$ & $29 / 9$ & $<0.05$ \\
\hline $\begin{array}{l}\text { Average age for disease onset, } \\
\text { years }\end{array}$ & $38.2 \pm 14$ & $38.7 \pm 14$ & $N S$ \\
\hline $\begin{array}{l}\text { Diagnosis of DCM during the } \\
\text { primary examination }\end{array}$ & $2(9 \%)$ & $8(21 \%)$ & $N S$ \\
\hline
\end{tabular}

Among RV-DCM patients during the primary examination, DCM was diagnosed only in $9 \%$ of cases vs. $21 \%$ of cases among DCM patients with BV-HF $(P<0.05)$. The higher percentage among patients with BV-HF was possibly caused by obvious signs of LV failure and the detectable LV dilatation. The majority of Group 1 patients were treated and observed with other diagnoses, such as chronic hepatitis, COPD, coronary heart disease, liver cirrhosis, etc.

Clinical evaluation of the patients revealed some features that depended on the character of myocardial failure. We analyzed the symptom scores to assess the differences (Table 2) between Groups.

Table 2.

Clinical characteristics of the studied patients

\begin{tabular}{|l|c|c|c|}
\hline \multicolumn{1}{|c|}{ Variable } & $\begin{array}{c}\text { Group 1 } \\
(\mathrm{n}=22)\end{array}$ & $\begin{array}{c}\text { Group 2 } \\
(\mathrm{n}=38)\end{array}$ & $P$ \\
\hline Dyspnea & $1.35 \pm 0.49$ & $1.42 \pm 0.51$ & 0.614 \\
\hline Patient's position in the bed & $0.89 \pm 0.16$ & $1.58 \pm 0.51$ & 0.000 \\
\hline Jugular venous distention & $1.05 \pm 0.72$ & $0.89 \pm 0.66$ & 0.394 \\
\hline Congestive moist rales & $0.75 \pm 0.58$ & $1.26 \pm 0.73$ & 0.009 \\
\hline Gallop rhythm & $0.40 \pm 0.50$ & $0.58 \pm 0.51$ & 0.200 \\
\hline Liver & $1.35 \pm 0.58$ & $1.37 \pm 0.68$ & 0.911 \\
\hline Edema & $1.40 \pm 0.82$ & $1.11 \pm 0.66$ & 0.145 \\
\hline
\end{tabular}

Thus, RV-DCM patients had fewer pronounced signs of LV failure: lower position of the head end of the bed $(0.89 \pm 0.16$ versus $1.58 \pm 0.51$, in Group 2, $P=0.000$ ) and less congestive 
moist rales in the lungs $(0.75 \pm 0.58$ versus $1.26 \pm 0.73$ in Group $2, P=0.019)$. Such indicators as jugular venous distention and edema in Group 1 patients were prevalent but not statistically significant.

ECG analysis revealed most significant differences in the incidence of "dextrogram" and the ratio of RV6/RVmax amplitude. Particularly, right axis deviation was registered in $16(80 \%)$ cases among RV-DCM patients and only in $4(10 \%)$ cases in DCM patients with BV-HF $(P=0.000)$. RV6/RVmax ratio reached $0.87 \pm 0.38$ and $2.98 \pm 1.29$ in Group 1 and Group 2 , respectively $(P=0.000)$. In addition, $8(40 \%)$ patients with RV-DCM had T- wave alternans, which was not recorded in Group $2(P=0.000)$, while a T-wave inversion occurred in $6(30 \%)$ and $13(32 \%)$ of cases in Group 1 and Group 2, respectively (Table 3 ). The patient proportion with persistent $\mathrm{AF}$ in Group 1 was slightly above that in Group 2; complete LBBB occurred only in DCM patients with BV-HF $(P=0.129)$, and incomplete RBBB was significantly more frequent in RV-DCM patients ( 5 vs. $1, P=0.04$ ). The same frequency of first-degree AV block occurred in both groups, but one RVDCM patient developed a complete AV block that required pacemaker implantation (Table 3).

Table 3.

ECG parameters of DCM patients

\begin{tabular}{|l|c|c|c|c|}
\hline \multicolumn{1}{|c|}{ Variable } & Group 1 & Group 2 & $P$ & $\chi^{2}$ \\
\hline $\begin{array}{l}\text { Right axis deviation, high R } \\
\text { wave in leads V1-V3 and } \\
\text { deep S wave in leads V5-V6, } \mathrm{n}\end{array}$ & 16 & 4 & 0.000 & 24.258 \\
\hline $\begin{array}{l}\text { T wave inversion in leads } \\
\text { V1-V3, without RBBB, } \mathrm{n}\end{array}$ & 8 & - & 0.000 & $\begin{array}{c}\text { Yates' } \chi 2 \\
12.952\end{array}$ \\
\hline $\begin{array}{l}\text { T wave inversion in leads } \\
\text { V5- V6 without LBBB, } \mathrm{n}\end{array}$ & 6 & 13 & 0.578 & 0.31 \\
\hline $\begin{array}{l}\text { Increases of QRS complex } \\
\text { duration >110ms in V1-V) }\end{array}$ & 4 & 5 & 0.8791 & $\begin{array}{c}\text { Yates' } \chi 2 \\
0.023\end{array}$ \\
\hline Permanent form of AF, n & 6 & 8 & 0.583 & 0.301 \\
\hline Complete LBBB, n & - & 6 & 0.129 & $\begin{array}{c}\text { Yates' } \chi 2 \\
2.305\end{array}$ \\
\hline Incomplete RBBB, n & 5 & 1 & 0.04 & $\begin{array}{c}\text { Yates' } \chi 2 \\
4.219\end{array}$ \\
\hline Complete RBBB, n & 3 & 2 & 0.518 & $\begin{array}{c}\text { Yates' } \chi 2 \\
0.418\end{array}$ \\
\hline Left posterior hemiblock, n & 3 & - & 0.085 & $\begin{array}{c}\text { Yates' } \chi 2 \\
2.961\end{array}$ \\
\hline Left anterior hemiblock, n & 1 & 4 & 0.747 & $\begin{array}{c}\text { Yates' } \chi 2 \\
0.104^{2}\end{array}$ \\
\hline First-degree AV block, n & 3 & 2 & 0.518 & $\begin{array}{c}\text { Yates' } \chi 2 \\
0.418\end{array}$ \\
\hline Complete AV block, n & 1 & - & 0.780 & $\begin{array}{c}\text { Yates' } \chi 2 \\
0.078\end{array}$ \\
\hline
\end{tabular}

A number of significant differences in the linear and volume indicators were revealed by comparative analysis of Echo-CG parameters (Table 4.) Despite the right-sided heart dilation ( $\mathrm{RV}=50.54 \pm 8.43 \mathrm{~mm}, \mathrm{RA}=47.98 \pm 9.92 \mathrm{~mm})$, the leftsided heart size remained in normal range $(\mathrm{LVEDD}=39.9 \pm 9.8$ $\mathrm{mm} ; \quad \mathrm{LVESD}=29.12 \pm 10.15 \mathrm{~mm} ; \mathrm{LA}=35.75 \pm 12.69 \mathrm{~mm}$ ) that is typical for RV-DCM patients. LV myocardial contractility also remained within normal range (LVEF $=67.09 \pm 10.0 \%$ ). Right and left heart dilatations with a decrease in inotropic myocardial function were noted in DCM patients with BV-HF.

Table 4.

Echo-CG parameters of DCM patients

\begin{tabular}{|l|c|c|c|}
\hline Parameter & Group 1 & Group 2 & $P$ \\
\hline Aortic Root, mm & $30.44 \pm 3.69$ & $29.11 \pm 4.71$ & 0.274 \\
\hline LA dimension, mm & $35.75 \pm 12.69$ & $47.48 \pm 5.49$ & 0.000 \\
\hline IVST, mm & $10.75 \pm 1.94$ & $9.62 \pm 1.64$ & 0.021 \\
\hline LVPWT, mm & $10.45 \pm 1.74$ & $9.75 \pm 1.95$ & 0.180 \\
\hline LVESD, mm & $29.12 \pm 10.15$ & $63,73 \pm 7,80$ & 0,000 \\
\hline LVEDD, mm & $39.9 \pm 9.8$ & $74.68 \pm 7.34$ & 0.000 \\
\hline LVEF, \% & $67.09 \pm 10.01$ & $30.59 \pm 7.13$ & 0.000 \\
\hline LVFS, \% & $19.63 \pm 5.59$ & $14,80 \pm 3,37$ & 0,000 \\
\hline RVEF, \% & $37.86 \pm 8.17$ & $47.2 \pm 9.31$ & 0.000 \\
\hline RV, mm & $50.54 \pm 8.43$ & $42.78 \pm 5.58$ & 0.000 \\
\hline RA, mm & $47.98 \pm 9.92$ & $42.98 \pm 5.57$ & 0.015 \\
\hline LVEDV, ml & $82.30 \pm 36.79$ & $296.29 \pm 68.61$ & 0.000 \\
\hline LVESV, ml & $27.90 \pm 16.59$ & $200.88 \pm 70.65$ & 0.000 \\
\hline LVSV, ml & $54.40 \pm 24.81$ & $95.42 \pm 27.64$ & 0.000 \\
\hline LVM, g & $179.45 \pm 67.13$ & $349.46 \pm 85.04$ & 0.000 \\
\hline Mean PAP, mmHg & $37.12 \pm 7.77$ & $44.57 \pm 10.75$ & 0.008 \\
\hline Comparative characteristics of LV/RV diastolic function \\
\hline LV PE, cm/sec & $0.73 \pm 0.23$ & $0.66 \pm 0.16$ & 0.228 \\
\hline LV PA, cm/sec & $0.44 \pm 0.21$ & $0.39 \pm 0.18$ & 0,367 \\
\hline LV PE/PA & $1.57 \pm 0.13$ & $1.61 \pm 0.11$ & 0.243 \\
\hline RV PE, cm/sec & $0.79 \pm 0.17$ & $0.67 \pm 0.14$ & 0.005 \\
\hline RV PA, cm/sec & $0.29 \pm 0.31$ & $0.39 \pm 0.12$ & 0.077 \\
\hline RV PE/PA & $2.64 \pm 0.23$ & $1.51 \pm 0.11$ & 0.000 \\
\hline
\end{tabular}

Almost all DCM patients had pulmonary arterial hypertension syndrome. Mean pulmonary pressure, defined as an indexed rate, was significantly higher in patients with classical DCM. All Group 1 patients had pseudonormal LVDD (PE/PA $=1.57 \pm 0.11$ ), but RVDD was worse in Group 2 patients compared to Group 1. The dysfunction found in Group 2 patients was the restrictive type, against the pseudonormal type in Group 1(2.64 \pm 0.23 and $1.57 \pm 0.11 ; P=0.000)$.

Results of biochemical and immune-enzyme analyses in DCM are shown in Table 5.

Table 5.

Biochemical parameters of DCM patients

\begin{tabular}{|l|c|c|c|}
\hline \multicolumn{1}{|c|}{ Variable } & Group 1 & Group 2 & $P$ \\
\hline Total bilirubin, mkmol/1 & $34.83 \pm 23.72$ & $24.44 \pm 9.01$ & 0.012 \\
-conjugated & $14.82 \pm 16.21$ & $6.76 \pm 3.51$ & 0.02 \\
-unconjugated & $23.26 \pm 14.58$ & $21.23 \pm 5.59$ & $N S$ \\
\hline ALT, IU/1 & $39.55 \pm 42.59$ & $44.92 \pm 46.78$ & $N S$ \\
\hline AST, IU/1 & $41.09 \pm 47.91$ & $37.33 \pm 27.84$ & $N S$ \\
\hline Plasma albumin, g/dl & $2.9 \pm 0.6$ & $3.16 \pm 0.48$ & $N S$ \\
\hline Total cholesterol, $\mathrm{mg} / \mathrm{dl}$ & $113.8 \pm 11.7$ & $107.3 \pm 8.8$ & 0.026 \\
\hline
\end{tabular}


A change in level of at least one of any of the functional markers of liver damage was identified in $81.8 \%$ of cases in RV-DCM patients, while this index was only $42.1 \%$ in Group $2(P=0.01)$. Hyperbilirubinemia was the most typical marker of the liver damage among examined patients, which was recorded in $91 \%$ of patients in Group 1 versus $58 \%$ of patients in Group 2. The laboratory analysis showed that the total bilirubin level was increased, mainly due to high values of unconjugated bilirubin fraction in both groups. The serum level of conjugated bilirubin was 2 times greater than the normal value only in Group 1 patients. TNF- $\alpha$ and CRP plasma concentrations were determined additionally in 9(41\%) and 14(37\%) patients of Group 1 and 2, respectively, and also in 10 healthy persons. The serum level of TNF- $\alpha$ was $59.7 \pm 1.8 \mathrm{pg} / \mathrm{ml}$ and $58.6 \pm 1.68 \mathrm{pg} / \mathrm{ml}$ in Group 1 and Group 2, respectively, compared to $29.2 \pm 1.4 \mathrm{pg} / \mathrm{ml}$ in healthy persons $(P<0.005$ in both cases $)$.

The increased serum CRP level was without significant differences between groups $(9.8 \pm 1.1 \mathrm{mg} / 1$ and $8.9 \pm 1.2 \mathrm{mg} / \mathrm{l}$; $P=0.084$ ) and more than three times higher than normal values $(2.3 \pm 0.6 \mathrm{mg} / 1 ; P<0.05$ compared to Groups 1 and 2$)$.

In the study of patient prognosis, it was noted that 5-year mortality was almost the same in both groups: $12(54.5 \%)$ and 18(47.4\%) in Group 1 and Group $2\left(\chi^{2}=0.287 ; P=0.592\right)$. Analysis of the causes of death revealed that fatal pulmonary embolism (PEmb) was a leading cause $(50 \%)$ in RV-DCM patients (Fig.1).
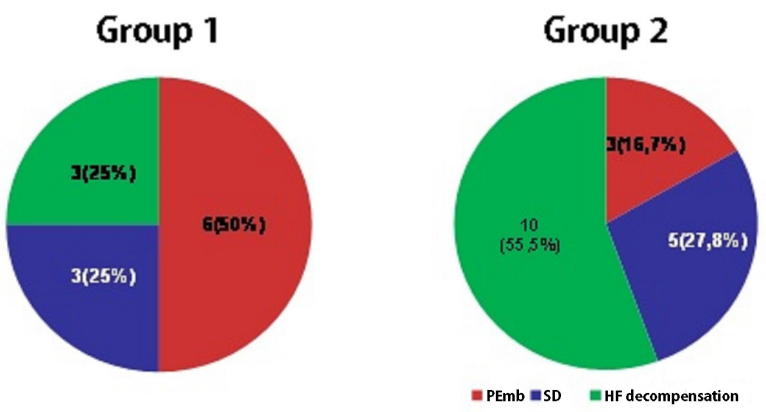

Fig. 1. Causes of death in DCM patients

This cause of death was established on the basis of acute symptoms and autopsy results of in-patients, as well as an interview with the relatives when they indicated the suddenly developed dyspnea, cyanosis, hemoptysis which preceded death. The unfavorable outcome of sudden death (SD) in $3(25 \%)$ patients of Group 1 occurred as a result of progressive decompensation of CHF. PEmb was the cause of death only in $3(16.7 \%$ ) cases in Group 2 patients (Yates' $\chi 2=2.388 ; P=0.122$ compared to Group 1). The majority of DCM patients with BV-HF (55.5\%) died due to HF progression (Yates' $\chi 2=1.635$; $P=0.201$ compared to Group 1). We also analyzed the frequency of patients' readmissions with CHF destabilization and nonfatal thromboembolic complications, such as acute ischemic stroke and PEmb. Thus, the average number of hospitalizations during the observation period was $8.5 \pm 3.2$ in Group 2 versus $9.3 \pm 2.5$ in Group $1(P>0.05)$. The cases of nonfatal stroke and PEmb were registered with different frequency, as expected, on the assumption of morphological and hemodynamic features of heart disease in comparison groups of patients. Acute destabilization of CHF with episodes of hemoptysis was registered in 15(68.2\%) of cases in RVCMP. Thromboembolism was verified by X-ray examination in some patients. The incidence of this outcome was $26,3 \%$ $\left(\chi^{2}=10.048 ; P=0.0015\right)$ in Group 2. Incidents of ischemic stroke or transient ischemic attack episodes were registered only in patients of Group 2 (7/18.4\%; Yates' $\left.\chi^{2}=2.97 ; P=0.08\right)$.

\section{Results and Discussion}

It is well known that cardiomyopathy, in particular DCM, is characterized by extremely poor prognosis and a high mortality rate. However, detection of possible differences in the course and outcome of various DCM clinical variants is very important. We focused on gender features of DCM and its clinical variant, RV-DCM, as an initially diagnosed condition. It is a common view that DCM occurs more frequently in men than in women $[2,13]$, which was confirmed by us. However, women significantly prevailed over men (2.7 times) among RV-DCM patients. It is not possible to confirm or deny this gender feature of RV-DCM because of the very limited publications on the subject. Almost all of them are characterized by descriptions of sporadic cases or small clinical studies. For example, a case of idiopathic dilatation and RV dysfunction in a young 16-year-old girl was described by K.Ishikawa et al.[13]. The monitoring results of 14 RV-DCM patients were published by D.Fitchett et al. [14]. At the same time, Indian researchers (Mohan JC et al., 1989) described RV-DCM in 10 patients, and noted the predominance of women [15]. Obviously, this issue can be clarified by a large epidemiological study. History has shown that RV-DCM patients enter cardiology departments very late due to misdiagnosis or a delay in diagnosis because of the lack the LV dysfunction, which is stereotypically associated with DCM. E. Amosova also indicated that most cases of RVDCM are diagnosed accidentally during patient examination for intercurrent diseases [16]. According to our data, we can assume that the isolated RV failure is clinically more severe than biventricular heart disease. J.Goldstein [17] noted that RVMI may result in severe hemodynamic compromise associated with a poor clinical outcome. The ischemic, dyskinetic right ventricular free wall exerts mechanically disadvantageous effects on biventricular performance. Depressed RV systolic function leads to a decrease in transpulmonary delivery of left ventricular (LV) preload, resulting in diminished cardiac output. [17]. The first report of concurrent right and left ventricular hypertrophy in response to pressure or volume overload of the right ventricle was made in 1982. In two pressure and volume overload models of canine right ventricular hypertrophy, D.F. Larson et al. have demonstrated significant hypertrophy of both the left and the right ventricles. The extent of hypertrophy was correlated positively to the extent of the increase in plasma epinephrine in both volume and pressure overload models [18].

Several studies of HF of ischemic etiology have shown 
that RV function is related to exercise tolerance and determines the severity of the patient's condition more than LV function, and that increasing RVEF is the measure of the effectiveness of revascularization in CHD patients with congestive HF [1921]. According to G. Karatasakis et al. [22], in patients with advanced heart failure, preserved RV function as indicated by an echocardiographically derived RV shortening $>1.25 \mathrm{~cm}$ was a strong predictor of survival.

In addition, we would like to mention the prevalence of some cases of AF in RV-DCM patients although the differences were not significant. The revealed features seemingly contradict the common pathogenesis mechanisms according to which the AF occurrence is mainly due to the appearance of abnormal impulses in LA remodeling from the mouths of the pulmonary veins and throughout the tissue. Nevertheless, the superior vena cava is one of the sources of ectopies that can initiate AF, which was determined in a study performed by M.Goya et al. [23]. Gaynor SL et al. [24] showed that in dogs with chronic RV pressure overload, RV systolic function was preserved, but diastolic function was impaired. To compensate, RA contractility increased, and the atrium became more distensible to maintain filling of the stiffened ventricle. This compensatory response of the right atrium likely plays an important role in preventing clinical failure in chronic pulmonary hypertension. In DCM, it has been histologically shown that a main cause of AF is fibrosis and reduction of myofibrils precisely, and to a lesser extent, remodeling and genetic contribution [25]. These data apparently explain the prevalence of AF in Group 1 patients.

Despite the right-sided heart dilatation in RV-DCM patients $(\mathrm{RV}=50.54 \pm 8.43 \mathrm{~mm}$ and $\mathrm{RA}=47.98 \pm 9.92 \mathrm{~mm})$, the size of the left-sided heart remained in the normal range $\quad(L V E D D=39.9 \pm 9.8 \mathrm{~mm} ; \quad L V E S D=29.1 \pm 10,1 \mathrm{~mm}$; $\mathrm{LA}=35.75 \pm 12.69 \mathrm{~mm})$. The results indicate intact $\mathrm{LV}$ myocardial contractility $(\mathrm{LVEF}=51.7 \pm 10.1 \%)$. The expected both right and left heart dilatation with marked reduction of inotropic miocardial function was registered in DCM patients with BV-HF. Polak J. F. et al [21] showed that in patients with depressed left ventricular ejection fraction (less than 40\%) and clinically evident congestive heart failure secondary to atherosclerotic coronary artery disease the reduction in right ventricular ejection fraction is a useful index not only for assessing biventricular function, but also for predicting patient outcome. These data were confirmed in other studies $[5,10]$.

Studies of the lesser circulation hemodynamics in 150 patients with dilatation cardiomyopathy and in 15 after heart transplantation [26] revealed secondary postcapillary pulmonary hypertension of more than $60 \mathrm{mmHg}$ in cases with dilatation cardiomyopathy with systolic pressure in the pulmonary artery (SPPA) in $30 \%$ of patients, transpulmonary gradient (TPG) of more than $15 \mathrm{~mm} \mathrm{Hg}$ and pulmonary vascular resistance (PVR) or more than 4 Wood's U in $15.3 \%$ of patients.

One of the anatomical features of the liver is its sophisticated dual blood supply, which makes it quite resistant to hemodynamic overload. It is established that even a slight increase of RA pressure in patients with heart failure may lead to hyperbilirubinemia [15]. Hepatic dysfunction is developed at the overpressure on $10 \mathrm{mmHg}$ and more in RA and a cardiac index reducing to lower than $1.51 / \mathrm{min} / \mathrm{m}^{2}$. In cases of "Cytolytic" syndrome with elevated aminotransferase levels, jaundice (defined as bilirubin higher than $3 \mathrm{mg} / \mathrm{dL}$ ) is a consequence of persistent and severe hypotension and hypoperfusion, such as acute LV failure, PE, and cardiogenic shock.

The results of our study also demonstrated that an increase in the level of liver enzymes was not so pronounced and widespread. An increase of at least one aminotransferase concentration higher than the norm occurred in 36.3\% and $30 \%$ in Group 1 and Group 2, respectively. Earlier studies have also shown that an increase in the level of liver aminotransferase does not usually exceed normal values by 2 to 3 times in patients with cardiovascular diseases [16].

Hyperbilirubinemia is caused by the violation of the synthesis, metabolism, transport and excretion of bilirubin. This condition is typical for a sufficiently wide variety of pathological conditions, including hepatitis, toxic lesions, biliary obstruction and hepatocellular dysfunction, and hereditary cholestatic syndromes. A secondary liver damage indicator is hyperbilirubinemia, which is characterized mainly by increasing unconjugated bilirubin. However, our results confirm once again the fact that serious damage to the rightsided heart and severe CHF leads to an increase in the level of conjugated bilirubin; at the same time, the jaundice may not manifest clinically before plasma bilirubin levels increase more than $3 \mathrm{mg} / \mathrm{dl}$. Currently, the clinical forms of liver disease in CHF are determined to be congestive hepatopathy, ischemic hepatitis, and cardiac hepatic fibrosis [19]. Changes of liver function test indicators in our study had moderate severity without development of varied clinical symptoms with rare exceptions(refractory ascites, encephalopathy, hemorrhagic complications), which indicated congestive hepatopathy.

The estimation of liver synthetic function is extremely important for the evaluation of the lesion depth. We identified a moderate hypoalbuminemia in both groups of patients (Table 5). It should be noted that the serum albumin does not change in acute viral hepatitis. Drug-induced liver injury, biliary obstruction, and hypoalbuminemia are more common in congestive genesis of liver lesions, enteropathy, nephropathy, and as a complication of heart failure.

In our work, we prospectively analyzed the prognosis of RV-DCM patients on medical therapy according to the CHF therapy guidelines $[27,28]$. The 5-year mortality of our patients was about $50 \%$, which is consistent with the 5-year survival of $50 \%$ to $70 \%$ reported in more recent studies on the prognosis of non-ischemic DCM [29-31]. The explicit prevalence of fatal pulmonary embolisms in RV-DCM patients is an important feature of RV-DCM outcomes. Ribeiro and colleagues were the first to suggest that patient with RV failure may have increased mortality. "RV dysfunction when diagnosis of PE is established is associated with mortality rate" [32].

\section{Conclusion}

The results of our investigations during many years of research have shown that the clinical incidence of RV- 
DCM was $7.3 \%$ among all forms of DCM. The study of life prognosis in patients with 2 forms of DCM showed that 5-year mortality of patients was about $50 \%$. Herewith, we detected the differences in causes of death depending on the type of heart damage, primarily development of fatal PE. Obviously, the results we anticipated have limitations, including lack of an analysis of the treatment regimens. Nevertheless, we believe that this pilot study, as well as a number of other small studies, contributes to the clarification of one of the least studied noncoronarogenic myocardial diseases-isolated RV-DCM.

\section{Competing interests}

The authors declare that they have no competing interests.

\section{References}

1. Bahler AS, Meller J, Brik H, Herman MV, Teichholz LE. Paradoxical motion of the interventricular septum with right ventricular dilatation in the absence of shunting: report of two cases. Am J Cardiol. 1976;38(5):654-7.

2. Richardson $\mathrm{P}$, McKenna W, Bristow M, Maisch B, Mautner B, O'Connell J, et al. Report of the 1995 World Organization International Society and Federation of Cardiology Task Force on the Definition and Classification of cardiomyopathies. Circulation. 1996; 93(5):841-2.

3. Coignard E, Blanchard B, Jault F, Dorent R, Vaissier E, Nataf $P$, et al. Alcoholic cardiomyopathy and cardiac transplantation /Coignard E., Blanchard B., Jault F. et al. Arch Mal Coeur.1998;91(1):45-51. [Article in French].

4. Homans DC. Peripartum cardiomyopathy.N Engl J Med.1985;312(22):1432-7.

5. Mestroni L, Maisch B, McKenna WJ, Schwartz K, Charron P, Rocco C,,et al. Guidelines for the study of familial dilated cardiomyopathies. Eur Heart J. 1999;20(2):93-102.

6. Matsui S, Murakami E, Takekoshi N, Tsuji S. Idiopathic dilated right ventricular cardiomyopathy: a report of eight cases. J Cardiogr. 1985;15(4):1027-38.

7. Samanta S, Vijayverghia R, Vaiphei K. Isolated idiopathic right ventricular dilated cardiomyopathy. Indian J Pathol Microbiol. 2011;54(1):164-6.

8. Ibsen HH, Baandrup U, Simonsen EE. Familial right ventricular dilated cardiomyopathy. $\mathrm{Br}$ Heart $\mathrm{J}$. 1985;54(2):156-9.

9. Rowland E, McKenna WJ, Sugrue D, Barclay R, Foale RA, Krikler DM. Ventricular tachycardia of left bundle branch block configuration in patients with isolated right ventricular dilatation. Clinical and electrophysiological features. Br Heart J. 1984;51:15-24.

10. Levine RA, Gibson TC, Aretz T, Gillam LD, Guyer DE, King ME, et al. Echocardiographic measurement of right ventricular volume. Circulation 1984; 69(3):497-505.

11. Gibson TC, Miller SW, Aretz T, Hardin NJ, Weyman AE. Method for estimation right ventricular volume by planes applicable to cross-sectional echocardiography: correlation with angiographic formulas. Am J Cardiol. 1985;55(13Pt 1):1584-8. 12. Elliott P, Andersson B, Arbustini E, Bilinska Z, Cecchi F, Charron P, et al. Classification of the cardiomyopaties: a position statement from the European Society of Cardiology Working Group on Myocardial and Pericardial Diseases. Eur Heart J. 2008; 29(2):270-6.

13. Ishikawa K, Yokoyama K, Araki T, Miura T, Goto T, Saito
H. A case of right ventricular cardiomyopathy, which involved left ventricle. Kokui To Junkan 1990;38(12):1269-72.

14. Fitchett DH, Sugrue DD, McArthur CG, Oakley CM. Right ventricular dilated cardiomyopathy. $\mathrm{Br}$ Heart $\mathrm{J}$. 1984;51(1):25-9.

15. Mohan JC, Chutani SK, Sethi KK, Arora R, Khalilullah M. Dominant right ventricular dilated cardiomyopathy: clinical, echocardiographic and haemodynamic profile. Indian Heart J 1989;41(3):177-81.

16. Amosova EN. Cardiomyopathy: A Guide. Kiev: Kniga Plus, 1999. [in Russian].

17. Goldstein JA. Right heart ischemia: pathophysiology, natural history, and clinical management. Prog Cardiovasc Dis. 1998; 40(4):325-41.

18. Larson DF, Womble JR, Copeland JG, Russell DH. Concurrent left and right ventricular hypertrophy in dog models of right ventricular overload. J Thorac Cardiovasc Surg. 1982 Oct; $84(4): 543-7$.

19. Baker BJ, Franciosa JA. Effect of the left ventricle on the right ventricle. Cardiovasc Clin. 1987;17(2):145-55.

20. Ostroumova EN, Kormer AY, Gureev SV Ermolenko AE. Ejection fraction of the right ventricle as an indicator of effectiveness of myocardial revascularization in patients with coronary heart disease and congestive heart failure. Kardiologiia. 1996; 4:57-61.

21. Polak JF, Holman BL, Wynne J, Colucci WS. Right ventricular ejection fraction: an indicator of increased mortality in patients with congestive heart failure associated with coronary artery disease. J Am Coll Cardiol. 1983; 2(2): 217-24.

22. Karatasakis GT, Karagounis LA, Kalyvas PA, Manginas A, Athanassopoulos GD, Aggelakas SA, et al. Prognostic significance of echocardiographically estimated right ventricular shortening in advanced heart failure. Am J Cardiol. 1998; 82(3):329-34.

23. Goya M, Ouyang F, Ernst S, Volkmer M, Antz M, Kuck KH. Electroanatomic mapping and catheter ablation of breakthroughs from the right atrium to the superior vena cava in patients with atrial fibrillation. Circulation. 2002; 106(11):1317-20.

24. Gaynor SL, Maniar HS, Bloch JB, Steendijk P, Moon MR. Right atrial and ventricular adaptation to chronic right ventricular pressure overload. Circulation. 2005; 112(9 Suppl):I212-8.

25. Mroczek AG, Atroschenko ES, Ostrovsky YP, et al. Diagnosis and treatment of atrial fibrillation. National guidelines. Minsk, 2010. [in Russian].

26. Shumakov VI, Kormer AIa, Kozakov EN, Chestukhin VV, Shemakin SIu. The hemodynamics of the lesser circulation before and after heart transplantation in patients with dilated cardiomyopathy. Grud Serdechnososudistaia Khir. 1993;6:47. [Article in Russian].

27. Hunt SA, Baker DW, Chin MH, Cinquegrani MP, Feldman AM, Francis GS,, et al. ACC/AHA Guidelines for the Evaluation and Management of Chronic Heart Failure in the Adult: Executive Summary: a report of the American College of Cardiology/American Heart Association Task Force on Practice Guidelines. Circulation 2001; 104: 2996-3007.

28. Hunt SA, Abraham WT, Chin MH, Feldman AM, Francis GS, Ganiats TG, et al. ACC/AHA 2005 Guideline Update for the Diagnosis and Management of Chronic Heart Failure in the Adult- Summary Article: a report of the American College of Cardiology/American Heart Association Task Force on 
Practice Guidelines. Circulation 2005; 112:154- 235.

29. Martins E, Cardoso JS, Campelo M, Amorim S, Moura B, Maciel MJ, Gonçalves FR. Survival of patients with familial dilated cardiomyopathy on optimal heart failure. Rev Port Cardiol. 2009; 28(3):263-8.

30. Felker GM, Thompson RE, Hare JM, Hruban RH, Clemetson DE, Howard DL, et al. Underlying causes and long-term survival in patients with initially unexplained cardiomyopathy. N Eng J Med 2000; 342(15): 1077-84.
31. Di Lenarda A, Pinamonti B, Mestroni L, Salvi A, Sabbadini G, Gregori D, et al. The natural history of dilated cardiomyopathy: a review of the Heart Muscle Disease Registry of Trieste. Ital Heart J Suppl 2004; 5(4):253-66. [Article in Italian].

32. Ribeiro A1, Lindmarker P, Juhlin-Dannfelt A, Johnsson H, Jorfeldt L. Echocardiography Doppler in pulmonary embolism: right ventricular dysfunction as a predictor of mortality rate. Am Heart J. 1997;134(3):479-87. 